\title{
COL11A1 is overexpressed in recurrent non-small cell lung cancer and promotes cell proliferation, migration, invasion and drug resistance
}

\author{
LIHUA SHEN $^{1,2^{*}}$, MIN YANG $^{3 *}$, QIONGHUA LIN $^{1}$, ZHONGWEI ZHANG $^{1,2}$, \\ BIAO ZHU ${ }^{1,2}$ and CHANGHONG MIAO ${ }^{1,2}$
}

${ }^{1}$ Department of Anaesthesia, Critical Care and Pain Medicine, Fudan University Shanghai Cancer Center, Shanghai 200032; ${ }^{2}$ Department of Oncology, Shanghai Medical College, Fudan University, Shanghai 200032;

${ }^{3}$ Department of Respiratory Diseases, Tianjin First Center Hospital, Tianjin 300192, P.R. China

Received September 5, 2015; Accepted December 7, 2015

DOI: $10.3892 / o r .2016 .4869$

\begin{abstract}
Collagen type XI $\alpha 1$ (COL11A1), a minor fibrillar collagen, has been demonstrated to be involved in cell proliferation, migration and the tumorigenesis of many human malignancies. Previous studies have shown that COL11A1 may be a valuable diagnostic marker for non-small cell lung carcinoma (NSCLC). However, its biological function in NSCLC progression remains largely unclear. In the present study, we investigated the expression levels of COL11A1 in different human NSCLC samples, and found that COL11A1 was overexpressed in NSCLC with lymph node metastasis and in recurrent NSCLC tissues. We also revealed that COL11A1 promoted the cell proliferation, migration and invasion of NSCLC cell lines in vitro. Furthermore, our results highlighted the importance of COL11A1 in chemoresistance to cisplatin. Mechanistically, we found that the effects of the overexpression of COL11A1 in NSCLC cells were mediated by Smad signaling. Collectively, our findings suggest that COL11A1 may sever as a biomarker for metastatic NSCLC, and can be used to predict recurrence after surgical resection. Therapeutic approaches targeting COL11A1 may facilitate the optimization of cisplatin treatment of NSCLC by overcoming chemoresistance.
\end{abstract}

Correspondence to: Dr Biao Zhu or Dr Changhong Miao, Department of Anaesthesia, Critical Care and Pain Medicine, Fudan University Shanghai Cancer Center, Shanghai 200032, P.R. China

E-mail: zhubiaozs@sohu.com

E-mail:miaochh@aliyun.com

*Contributed equally

Key words: lung cancer, COL11A1, chemoresistance, relapse, Smad signaling

\section{Introduction}

Lung cancer is the most common type of cancer, and is the leading cause of human cancer-related deaths $(1,2)$. Non-small cell lung carcinoma (NSCLC) accounts for approximately $85 \%$ of all cases of human lung cancer, including all types of epithelial lung cancer except small cell lung carcinoma (SCLC) (3). Generally, the 5-year survival rate of lung cancer patients is approximately $15 \%$ (2). For patients with different stages of lung cancer, the 5-year relative survival rate varies dramatically from 49 to $2 \%(2,4)$. However, approximately $70 \%$ of patients with lung cancer were found to present with intrathoracic or extrathoracic metastasis at initial diagnosis $(3,5)$. Thus, it is crucial to detect lung cancer at an early stage, and to suppress the spread of primary cancer.

Currently, surgical resection remains the single most successful treatment for patients with early-stage NSCLC $(6,7)$. However, despite optimal surgical treatment, approximately half of the patients with NSCLC develop recurrence and succumb to the disease, even though they present with histologically negative lymph nodes $(8,9)$. While bone is the most common target of distant metastasis from lung cancer, recurrent NSCLC is often systemic $(4,8)$. Although the mechanisms of recurrent NSCLC remain unclear, several molecules have been reported to predict the recurrence of NSCLC. These include EphA2 (EPH receptor A2) receptor tyrosine kinase, USP17 and DNA methylation markers (10-12).

The collagen type XI $\alpha 1$ (COL11A1) gene encodes one of the two $\alpha$ chains of type XI collagen, a minor fibrillar collagen (13). As a major component of the extracellular matrix $(\mathrm{ECM})$, collagens are involved in the regulation of multiple biological processes, including cell proliferation, differentiation and migration $(14,15)$. Type XI collagen is a heterotrimer, which is mainly expressed in the cartilage extracellular matrix, and is essential for skeletal morphogenesis (16). Mutations of COL11A1 are also associated with type II Stickler syndrome and Marshall syndrome $(17,18)$. In regard to tumor formation and development, COL11A1 was reported to promote tumor progression in ovarian cancer, and head and neck squamous cell cancer (HNSCC) (19-21). COL11A1 has also been shown to 
be a potential biomarker for colon cancer and $\operatorname{NSCLC}(22,23)$. However, the role of COL11A1 in NSCLC progression and relapse remains largely unknown. In the present study, we found that expression of COL11A1 was upregulated in metastatic and recurrent NSCLC. We further investigated the role of COL11A1 in the regulation of cell viability, migration and drug resistance in NSCLC cell lines.

\section{Materials and methods}

Reagents and antibodies. TRIzol reagent and Lipofectamine 2000 were purchased from Invitrogen (Carlsbad, CA, USA). The First Strand cDNA Synthesis kit and SYBR Premix Taq were purchased from Takara (Dalian, Liaoning, China). MTT [3-(4,5-dimethyl-2-thiazolyl)-2,5-diphenyl-2H-tetrazolium bromide], bromodeoxyuridine (BrdU), anti-BrdU antibody and Smad signaling pathway inhibitor LND-193189 were purchased from Sigma (St. Louis, MO, USA). LND-193189 (100 nM) was used for cell treatment. DAPI, the BCA protein assay kit and the ECL Plus kit were obtained from Beyotime Institute of Biotechnology (Beijing, China). BD BioCoat Matrigel invasion chambers were obtained from BD Biosciences (San Jose, CA, USA). Primary antibodies against human COL11A1 and cleaved caspase-3 were obtained from Abcam (Cambridge, MA, USA). Anti-p-Smad2, anti-Smad2 and anti-GAPDH were purchased from Santa Cruz Biotechnology (Santa Cruz, CA, USA). The horseradish peroxidase-conjugated anti-rabbit and anti-mouse IgG secondary antibodies were purchased from Santa Cruz Biotechnology. Biotinylated- and Cy3-conjugated anti-rabbit secondary antibodies were from Boster (Wuhan, Hubei, China).

Patient samples. A total of 65 samples from NSCLC patients ranging in age from 20-75 years were surgically obtained at the Department of Thoracic Surgery at Fudan University Shanghai Cancer Center. NSCLC was diagnosed according to surgical and pathological findings, which were based on the guidelines described by the 6th edition of AJCC/UICC (Table I). After explaining the purpose of the study, written informed consent was obtained from each patient. Karnofsky performance scale (KPS) score for all patients was $\geq 60$ points. Patients were excluded if they had received any prior treatments involving chemotherapy, radiotherapy or immunotherapy, or presented with other malignant diseases. Recurrent tumor tissues were obtain from 5 NSCLC patients who had received at least three cycles of standard chemotherapy consisting of intravenous (i.v.) cisplatin after surgery. This study was approved by the Institutional Ethics Review Boards of Fudan University Shanghai Cancer Center.

Cell culture and transfection. The human NSCLC cell lines (A549, H23, H520 and H1975) were purchased from the American Type Culture Collection (ATCC; Manassas, VA, USA) and cultured in RPMI-1640 medium (Gibco, Rockville, MD, USA) supplemented with $10 \%$ fetal calf serum (FBS), $100 \mathrm{U} / \mathrm{ml}$ penicillin $\mathrm{G}, 100 \mathrm{mg} / \mathrm{ml}$ streptomycin sulfate and $2 \mathrm{mmol} / \mathrm{l}$ glutamine (all from Gibco) at $37^{\circ} \mathrm{C}$ in a humidified incubator under an atmosphere of $5 \% \mathrm{CO}_{2}$ in air.

Human COL11A1 cDNA was amplified from $\mathrm{H} 23$ cells by PCR and constructed into the pcDNA3.1 vector using NheI and NotI restriction sites (forward primer sequences, ATAAGA ATGCGGCCGCATGGAGCCGTGGTCCTCTAGGT; and reverse primer sequences, ATAAGAATGCGGCCGCTTAGC CAAGAAAACAAACAGGACCAACTTC. COL11A1 siRNA and control siRNA were purchased from Santa Cruz Biotechnology. Transfection of the vector or siRNA to cells was performed using Lipofectamine 2000 according to the manufacturer's protocol.

Quantitative real-time $R T-P C R$ ( $q R T-P C R)$. Total RNA was extracted with TRIzol reagent from the NSCLC samples and cell lines according to the manufacturer's instructions. Total RNA $(5 \mu \mathrm{g})$ was used for reverse transcription using the First Strand cDNA Synthesis kit. The expression of mRNA was examined by qRT-PCR with SYBR Premix Taq and Applied Biosystems 7500 Sequence Detection system. The relative expression levels of mRNA were normalized to GAPDH expression, and the amplification results for qRT-PCR were calculated using the $2^{-\Delta \Delta \mathrm{Ct}}$ method. PCR reaction was performed using COL11A1 primers: 5'-TGGTGATCAGAAT CAGAAGTTCG-3', (forward) and 5'-AGGAGAGTTGAGAA TTGGGAATC-3' (reverse); and GAPDH, 5'-GTGGACATCC GCAAAGAC-3' (forward) and 5'-AAAGGGTGTAACGCAA CTA-3' (reverse).

Immunohistochemistry. The paraffin-embedded tissue samples from postoperative patients were sectioned into $5-\mu \mathrm{m}$ slices and embedded with paraffin after fixation with $10 \%$ formaldehyde. The samples were then deparaffinized in xylene, rehydrated and quenched the endogenous peroxidase activity by $3 \%$ hydrogen peroxide. Non-specific binding was blocked with $1 \%$ bovine serum albumin. The sections were then incubated overnight at $4^{\circ} \mathrm{C}$ with the COL11A1 primary antibody, and subsequently with the horseradish peroxidaseconjugated secondary antibody. The peroxidase was then developed by 3-amino-9-ethylcarbazole (AEC).

MTT and cell number counting assay. The MTT assay was used to assess cell proliferation and viability. In brief, the transfected NSCLC cells were seeded at a density of $2.5 \times 10^{3}$ cells/well in a $100 \mu 1$ volume of medium in 96-well plates and allowed to attach overnight. MTT (20 $\mu \mathrm{l}$ at $5 \mathrm{mg} /$ $\mathrm{ml})$ was added to the medium after treatment. After incubation at $37^{\circ} \mathrm{C}$ for $4 \mathrm{~h}$, the supernatant was aspirated, and $100 \mu \mathrm{l}$ DMSO was added to each well to dissolved the precipitates. Absorbance was then measured at $570 \mathrm{~nm}$ using a 96-well microplate reader. The survival ratio was calculated using the following equation: Survival ratio $(\%)=\mathrm{OD}_{\text {treated }} / \mathrm{OD}_{\text {control }}$ $\mathrm{x} 100$. For cell counting, NSCLC cells were plated onto $35-\mathrm{mm}$ dishes at $2 \times 10^{3}$ cells/dish. Cells were trypsinized and counted with a hemocytometer on day $0,1,2,3,4,5$ and 6 .

BrdU assay. The BrdU assay was performed to analyze cell proliferation according to the manufacturer's recommendations. NSCLC cells were seeded on a 4-well chamber slide and cultured in growth medium overnight. BrdU-labeled medium was then changed and incubated at $37^{\circ} \mathrm{C}$ for $3 \mathrm{~h}$. Cell medium was removed and the cells were fixed with ethanol for $20 \mathrm{~min}$ at $-20^{\circ} \mathrm{C}$. The cells were permeabilized with $0.1 \%$ Triton $\mathrm{X}-100$ in phosphate-buffered saline (PBS) and blocked with 
Table I. Correlation between COL11A1 and the clinicopathological characteristics of the 65 NSCLC patients.

\begin{tabular}{|c|c|c|c|c|}
\hline \multirow[b]{2}{*}{ Features } & \multirow{2}{*}{$\begin{array}{c}\text { No. of } \\
\text { patients }\end{array}$} & \multicolumn{2}{|c|}{ COL11A1 } & \multirow[b]{2}{*}{ P-value } \\
\hline & & Low $(\%)$ & $\operatorname{High}(\%)$ & \\
\hline All patients & 65 & $32(49.2)$ & $33(50.8)$ & \\
\hline Age (years) & & & & 0.540 \\
\hline$<60$ & 35 & $16(45.7)$ & $19(54.3)$ & \\
\hline$\geq 60$ & 30 & $16(53.3)$ & $14(46.7)$ & \\
\hline Gender & & & & 0.113 \\
\hline Male & 47 & $26(53.2)$ & $21(46.8)$ & \\
\hline Female & 18 & $6(33.3)$ & $12(66.7)$ & \\
\hline Smoking status & & & & 0.543 \\
\hline Smoker & 26 & $14(53.8)$ & $12(46.2)$ & \\
\hline Non-smoker & 39 & $18(46.1)$ & $21(53.8)$ & \\
\hline Histology & & & & $0.285^{\mathrm{a}}$ \\
\hline SCC & 21 & $10(47.6)$ & $11(52.4)$ & \\
\hline Adenocarcinoma & 32 & $20(62.5)$ & $12(37.5)$ & \\
\hline Other $^{\mathrm{b}}$ & 12 & $2(16.7)$ & $10(83.3)$ & \\
\hline Tumor size $(\mathrm{cm})$ & & & & 0.001 \\
\hline$<3$ & 24 & $18(75.0)$ & $6(25.0)$ & \\
\hline$\geq 3$ & 41 & $14(34.1)$ & $27(65.9)$ & \\
\hline TNM stage & & & & 0.015 \\
\hline I-II & 39 & $24(61.5)$ & $15(38.5)$ & \\
\hline III-IV & 26 & $8(30.8)$ & $18(69.2)$ & \\
\hline Lymph node status & & & & 0.018 \\
\hline Metastasis & 36 & $13(36.1)$ & $23(63.9)$ & \\
\hline Non-metastasis & 29 & $19(65.5)$ & $10(34.5)$ & \\
\hline Differentiation & & & & 0.035 \\
\hline Well and moderate & 28 & $18(64.3)$ & $10(35.7)$ & \\
\hline Poor & 37 & $14(37.8)$ & $23(62.2)$ & \\
\hline
\end{tabular}

${ }^{a} 0.034$, comparison between SCC and adenocarcinoma. ${ }^{b}$ Other, other NSCLC including adenosquamous carcinoma, large-cell carcinoma, mucoepidermoid carcinoma and carcinosarcoma. SCC, squamous cell carcinoma.

3\% FBS in PBS solution. After several washes with PBS, the cells were incubated with the anti-BrdU reagent for $30 \mathrm{~min}$ at $37^{\circ} \mathrm{C}$. The nuclei were then counterstained with DAPI. Images of each treatment were captured with an Olympus inverted microscope.

Wound-healing assay. The wound-healing assay was used to evaluate the cancer cell motility capacity. In brief, the transfected NSCLC cells were seeded in 6-well plates and cultured overnight. When the culture reached nearly $90 \%$ confluency, the cell layer was wounded by dragging a 1,000- $\mu$ l sterile pipette tip through the monolayer and washed with PBS twice to remove cellular debris. Cells were then cultured for up to $48 \mathrm{~h}$ with growth medium. Photographic images of the plates were acquired under a microscope, and the relative surface traveled by the leading edge was assessed.
Transwell assay. Cell invasion activity was assessed using 24-well BD BioCoat Matrigel Invasion chambers $(8-\mu \mathrm{m}$ pores, growth factor reduced) according to the manufacturer's instructions. Transfected NSCLC cells $\left(5 \times 10^{4}\right.$ cells $\left./ \mathrm{ml}\right)$ were loaded into the top chamber with serum-free media. In the lower chamber, $450 \mu \mathrm{l}$ of growth medium with $10 \%$ FBS was added. After $24 \mathrm{~h}$ of cultivation, the medium was removed and the Transwell chamber was gently wiped with a cotton swab. The migrated cells were fixed in $4 \%$ paraformaldehyde, stained with crystal violet solution and counted under a microscope.

Western blot analysis. NSCLC cells were washed with PBS and incubated in RIPA buffer (150 mM NaCl, $1 \% \mathrm{NP}-40$, $0.5 \%$ sodium deoxycholate, $0.1 \%$ SDS, $50 \mathrm{mM}$ Tris $\mathrm{pH} 8.0$, $5.0 \mathrm{mM}$ EDTA pH 8.0, $0.5 \mathrm{mM}$ dithiothreitol and $1 \mathrm{mM}$ phenylmethylsulfonyl fluoride) containing protease inhibitor on ice for $30 \mathrm{~min}$, and centrifuged at $12,000 \mathrm{x} \mathrm{g}$ for $15 \mathrm{~min}$ at $4{ }^{\circ} \mathrm{C}$. The protein concentration was determined using the BCA protein assay kit, and equal amounts of total protein were separated by $10 \%$ SDS-PAGE, and the protein was then transferred from the gel to a nitrocellulose membrane. The nitrocellulose membrane was then blocked with 5\% BSA for $1 \mathrm{~h}$. The membrane was then probed with a specific primary antibody and gently shacked at $4{ }^{\circ} \mathrm{C}$ overnight. The next day, the membrane was washed three times with TBST buffer, and incubated with the secondary antibodies for $1 \mathrm{~h}$ at room temperature. Images were acquired using the ECL Plus kit.

Statistical analysis. Data were analyzed using SPSS software 19.0 for Windows (SPSS, Chicago, IL, USA). Results are represented as the mean value of at least three different experiments and expressed as the mean \pm SD and analyzed by t-test or one-way ANOVA. $\mathrm{P}<0.05$ was considered to indicate a statistically significant result.

\section{Results}

Overexpression of COL11A1 in NSCLC. COL11A1 has been reported to be upregulated in NSCLC and to be correlated with lymph node metastasis and poor prognosis (22). However, its function in NSCLC is still unknown. To investigate the role of COL11A1 in NSCLC development and recurrence, we first examined COL11A1 expression in 65 NSCLC tissues. When compared with the adjacent normal tissues, the expression of COL11A1 was found to be overexpressed in the NSCLC samples (Fig. 1A). We then compared COL11A1 expression in 36 NSCLC samples with lymph node metastasis with 29 patients without lymph node metastasis. As shown in Fig. 1B, COL11A1 was significantly upregulated in NSCLC tissues with lymph node metastasis. From five primary and paired recurrent NSCLC tissues, COL1A1 was found to be significantly increased in all recurrent samples (Fig. 1C). We next performed immunohistochemistry for COL11A1 in the primary and recurrent NSCLC tissues. COL11A1 staining of the recurrent cancer tissues was obviously stronger than that of the primary NSCLC (Fig. 1D).

COL11A1 promotes cell proliferation, migration and invasion of NSCLC cells. To evaluate the functional effect of COL11A1, we examined COL11A1 expression in four NSCLC cell lines 
A

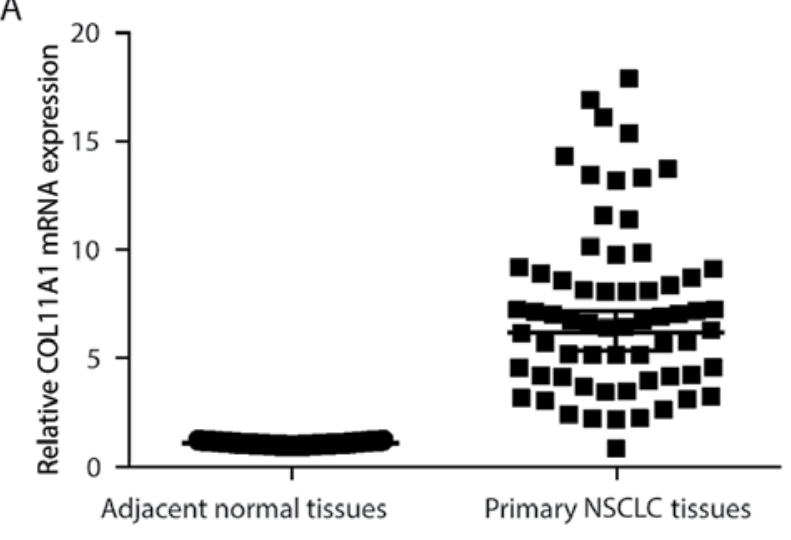

C

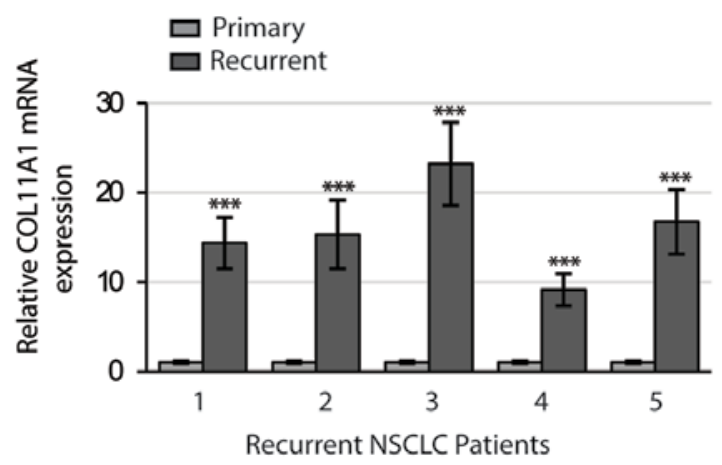

B

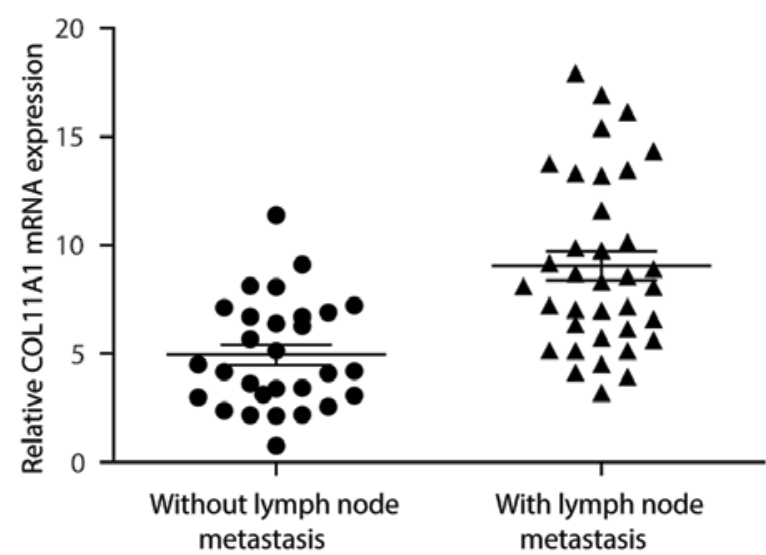

D

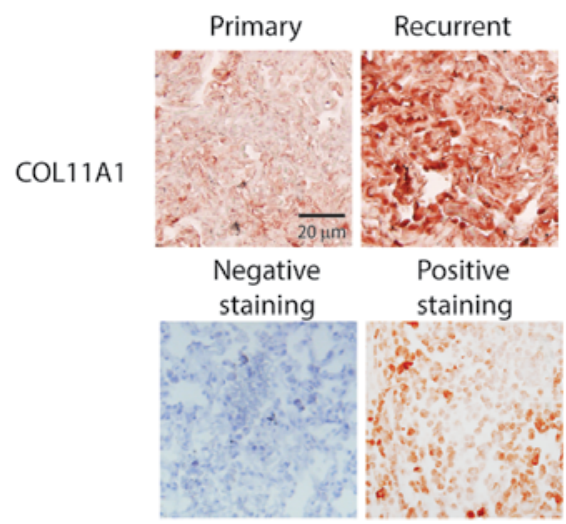

Figure 1. Overexpression of COL11A1 in NSCLC. (A) COL11A1 expression in 65 NSCLC samples compared to adjacent normal tissues analyzed by qRTPCR $(\mathrm{P}<0.001)$. (B) qRT-PCR analysis was used to analyze the relative expression of COL11A1 in NSCLC samples with and without lymph node metastasis $(\mathrm{P}<0.001)$. (C) Expression of COL11A1 in primary and paired recurrent NSCLC tissues from five patients analyzed by qRT-PCR. ${ }^{* * *} \mathrm{P}<0.001$ compared to primary tissues. (D) Representative immunohistochemical staining of COL11A1 in primary and recurrent NSCLC tissues of a single patient. Staining using PBS on samples from the same NSCLC patient is presented as the negative staining control. Staining of COL11A1 in ovarian cancer tissues is presented as the positive staining control.

(A549, H23, H520 and H1975). Among these four cell lines, $\mathrm{H} 23$ cells with endogenous low COL11A1 expression and H520 cells with high COL11A1 expression were selected for in vitro studies (Fig. 2A). Western blot assays for COL11A1 expression were used to analyze the transfection efficiency in the H520 cells transfected with COL11A1 siRNA and H23 cells transfected with the COL11A1 plasmid (Fig. 2B). These cells were then subjected to MTT, cell counting and BrdU cell proliferation assays. Knockdown of COL11A1 in the H520 cells significantly inhibited cell proliferation. Conversely, ectopic overexpression of COL11A1 in the H23 cells markedly promoted cell proliferation (Fig. 2C and D). To determine whether COL11A1 regulates cell migration and invasion, we performed wound-healing and Transwell assays in the COL11A1-silenced H520 cells and the COL11Aoverexpressing $\mathrm{H} 23$ cells. As shown in Fig. 3, depletion of COL11A1 reduced NSCLC cell migration and invasion ability, while an increase in COL11A1 expression enhanced cell migration and invasion.

COL11A1 is upregulated by cisplatin in NSCLC cells and mediates cell sensitivity to cisplatin. To determine the active mechanism of COL11A1 that may contribute to the drugresistant phenotype, we treated NSCLC H520 and H23 cells with different concentrations of cisplatin $(0,2,4$ or $8 \mu \mathrm{mol} / \mathrm{l})$, and analyzed COL11A1 mRNA levels by qRT-PCR. As shown in Fig. 4A, a gradual increase in COL11A1 mRNA levels was observed in both the H520 and H23 cells in response to the cisplatin treatment. Consistently, western blot analysis further confirmed the cisplatin-induced COL11A1 expression (Fig. 4B). Moreover, we treated the H520 and H23 cells with $8 \mu \mathrm{mol} / 1$ cisplatin and tested the COL11A1 mRNA levels during a 24-h time period. COL11A1 mRNA reached a peak at $12 \mathrm{~h}$ and was increased 2-fold when compared to its level at $0 \mathrm{~h}$ (Fig. 4C). To assess whether COL11A1 mediates cell sensitivity to cisplatin, we performed MTT cell viability assays following treatment of cisplatin with different concentrations $(0,2,4,8,16,32$ or $64 \mu \mathrm{mol} / \mathrm{l})$. Cell viability was decreased by cisplatin in a dose-dependent manner in both the H520 and $\mathrm{H} 23$ cells. Knockdown of COL11A1 shifted the survival curve of H520 cells downwards, while overexpression of COL11A1 increased $\mathrm{H} 23$ cell survival (Fig. $5 \mathrm{~A}, \mathrm{IC}_{50}$ of $30.72 \mu \mathrm{mol} / 1$ in control siRNA vs. $12.62 \mu \mathrm{mol} / 1$ in COL11A1 siRNA-transfected $\mathrm{H} 520$ cells; $\mathrm{IC}_{50}$ of $29.04 \mu \mathrm{mol} / \mathrm{l}$ in vector control vs. $47.33 \mu \mathrm{mol} / 1$ in COL11A1-transfected H520 cells). We further analyzed the cell viability after treatment with $8 \mu \mathrm{mol} / \mathrm{l}$ cisplatin at different time-points $(0,12,24,36,48,60$ and $72 \mathrm{~h})$. COL11A1 silencing resulted in a significant reduction in cell 
A

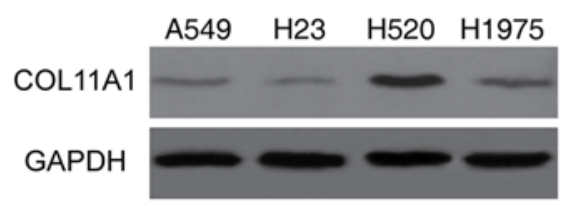

C
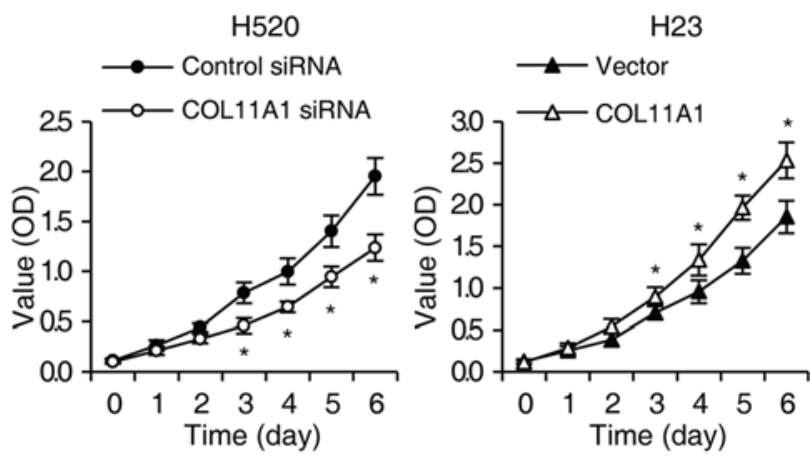

E

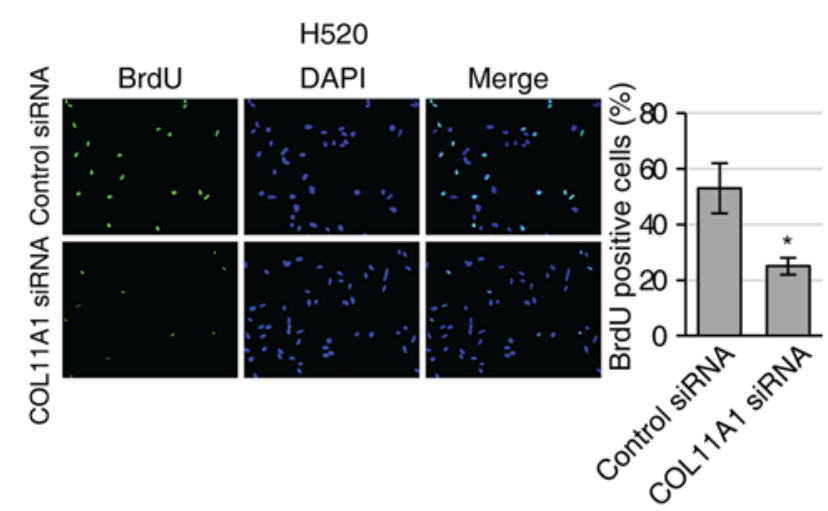

B

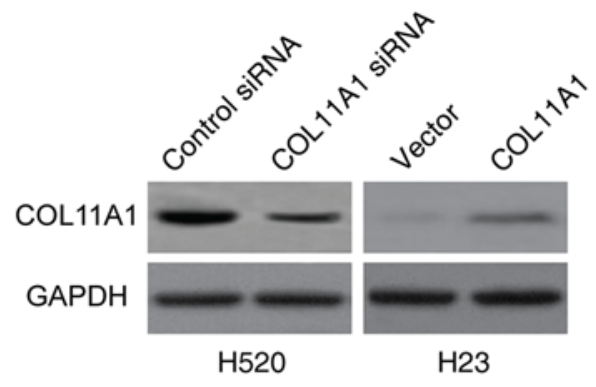

D
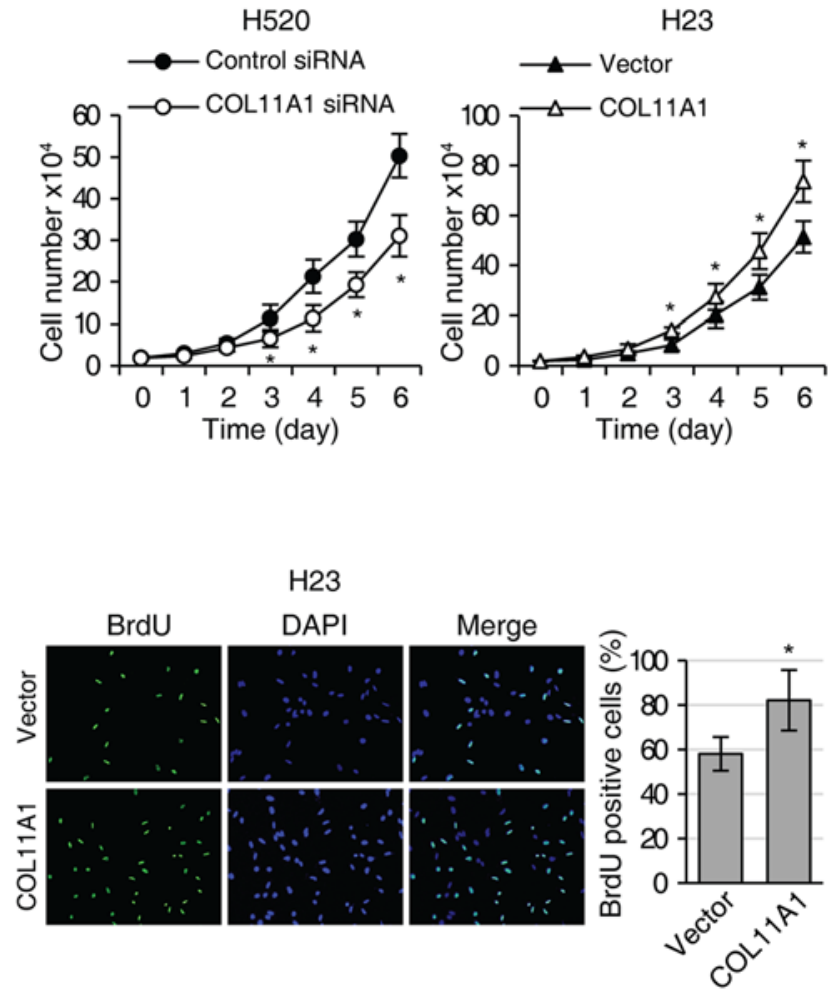

Figure 2. COL11A1 promotes NSCLC cell proliferation. (A) COL11A1 expression was analyzed by western blot analysis in four NSCLC cell lines (A549, H23, H520 and H1975). (B) Western blot analysis was used to examine COL11A1 expression in COL11A1-silenced H520 cells and COL11A1-overexpressing H23 cells. MTT (C), Cell Counting (D) and BrdU (E) assays were used to analyze cell proliferation in the COL11A1-silenced H520 cells and COL11A1overexpressing $\mathrm{H} 23$ cells. Represented images of BrdU assays are showed at $\mathrm{x} 40$ magnification. ${ }^{*} \mathrm{P}<0.05$ compared with the control cells.

viability. Conversely, COL11A1 overexpression enhanced cell viability (Fig. 5B).

COL11Al activates Smad signaling in NSCLC cells. COL11A1 has been reported to regulate the Smad signaling pathway (19). To address the intrinsic mechanisms by which COL11A1 regulates NSCLC cell tumorigenesis, we analyzed the effect of COL11A1 expression on Smad pathway activity. Downregulation of COL11A1 decreased $\mathrm{p}-\mathrm{Smad} 2$, and upregulation of COL11A1 increased p-Smad2 (Fig. 6A). We next performed MTT, wound-healing and Transwell assays using the COL11A1-overexpressing $\mathrm{H} 23$ cells in the presence or absence of LND-193189, a Smad signaling inhibitor. As shown in Fig. 6B-D, overexpression of COL11A1 promoted NSCLC cell proliferation, migration and invasion, which was abolished by inhibition of Smad signaling. Moreover,
LND-193189 was found to abrogate cisplatin resistance induced by COL11A1 (Fig. 6E).

\section{Discussion}

NSCLC is the most common type of lung cancer. According to tumor size and metastatic behavior, NSCLC is divided into different stages (24). Surgery, chemotherapy, radiation therapy and combined treatment options are used, mainly based on the stage of the cancer (5). However, the long-term survival of NSCLC patients after R0 resection is less than $50 \%(25,26)$. In addition, many recurrences are systemic, likely due to the presence of occult micrometastases beyond the surgical resection (10). Hence, the pathological stage may be independently associated with tumor relapse (27). In the present study, we found that COL11A1 expression was markedly upregulated in 
A H520
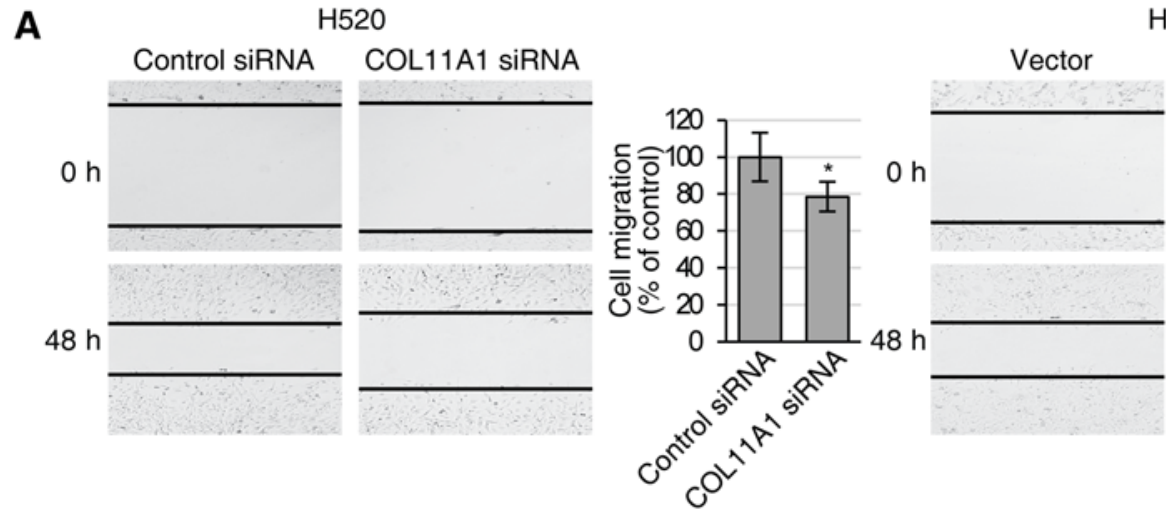

$\mathrm{H} 23$

COL11A1

\section{B}
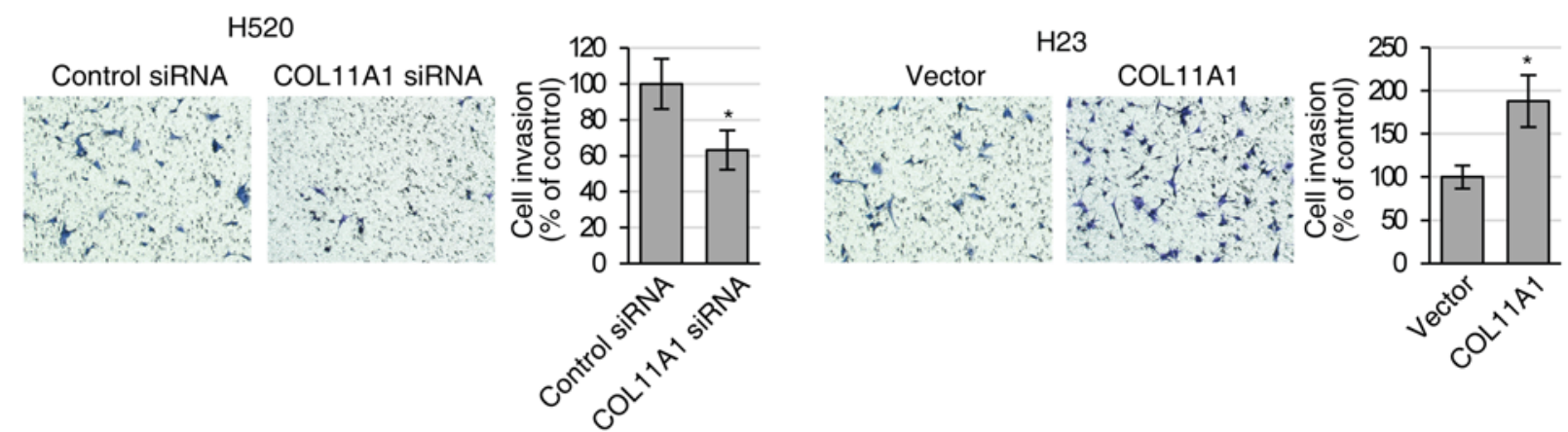

Figure 3. COL11 A1 enhances the migration and invasion of NSCLC cells. (A) Wound-healing assays were used to analyze the cell migration ability in the COL11A1-silenced H520 cells and COL11A1-overexpressing H23 cells. (B) Transwell assays were used to analyzed cell invasion ability in the COL11A1silenced H520 cells and COL11A1-overexpressing H23 cells. All value for the invasion and migration assays were normalized by cell proliferation results under the same treatment conditions. ${ }^{*} \mathrm{P}<0.05$ compared with the control cells.

A

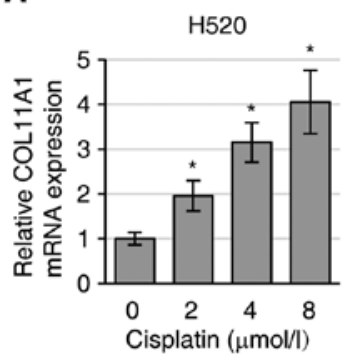

C

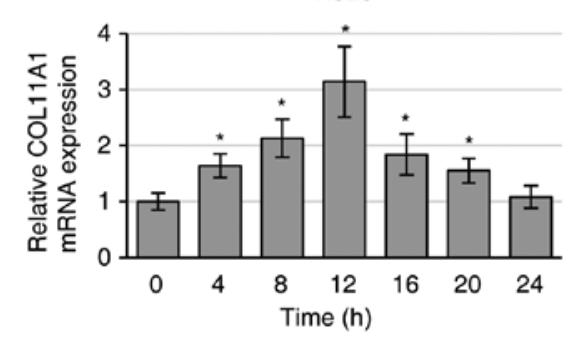

B
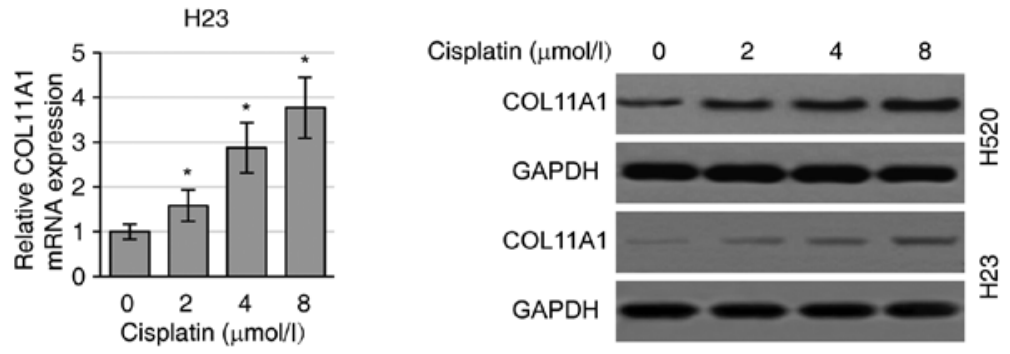

$\mathrm{H} 23$

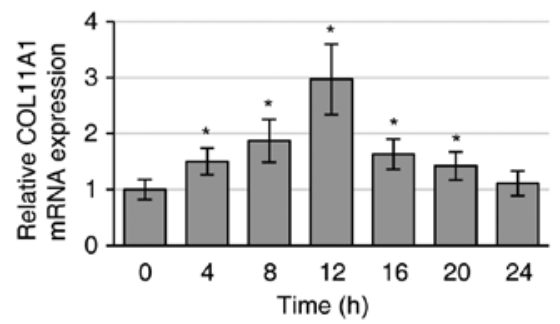

Figure 4. Expression of COL11A1 is induced by cisplatin in NSCLC cells. (A) mRNA levels of COL11A1 were analyzed by qRT-PCR in H520 and H23 NSCLC cells after treatment with increasing concentrations of cisplatin $(0,2,4$ or $8 \mu \mathrm{mol} / 1)$ for $48 \mathrm{~h}$. "P<0.05 compared with cisplatin $(0 \mu \mathrm{mol} / 1)$. (B) Protein levels of COL11A1 were analyzed by western blot analysis in the $\mathrm{H} 520$ and $\mathrm{H} 23$ cells after treatment with increasing concentrations of cisplatin as indicated for $48 \mathrm{~h}$. (C) qRT-PCR analysis was used to analyze mRNA expression of COL11A1 in the H520 and H23 cells after treatment with cisplatin $(8 \mu$ mol/l) at different time-points $(0,4,8,12,16,20$ and $24 \mathrm{~h}) .{ }^{*} \mathrm{P}<0.05$ compared with the $0 \mathrm{~h}$ group.

the recurrent NSCLC tissues, indicating that COL11A1 may be a novel biomarker for metastatic progression and the potential recurrence of NSCLC. In addition, there are 3 main subtypes of NSCLC: squamous cell carcinoma, adenocarcinoma, and large cell (undifferentiated) carcinoma. Wang et al reported that COL11A1 and integrin $\alpha-11$ are often overexpressed in 
A

H520

$\longrightarrow$ - Control siRNA

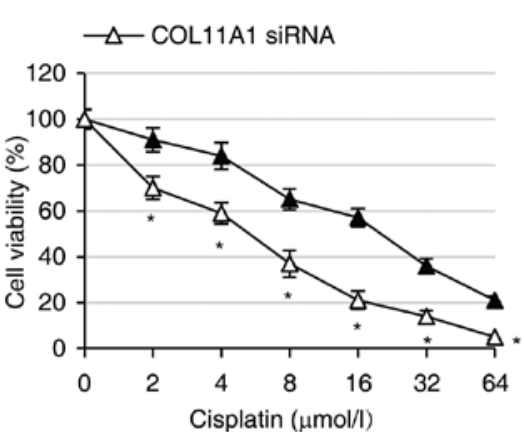

$\mathbf{B}$

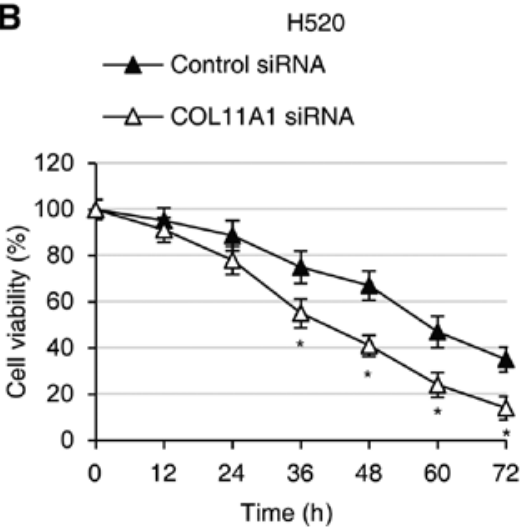

$\mathrm{H} 23$

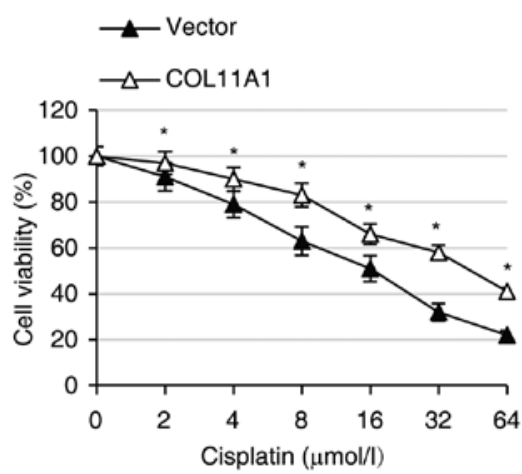

H23

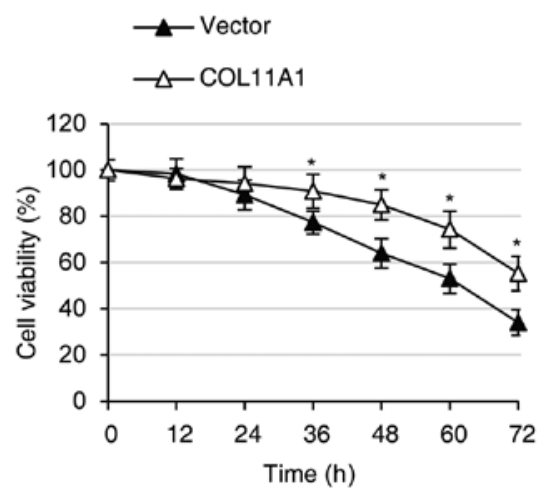

Figure 5. Regulation of COL11A1-mediated sensitivity to cisplatin in NSCLC cells. (A) MTT cell viability assays in the COL11A1-silenced H520 cells and COL11A1-overexpressing H23 cells treated with increasing concentrations of cisplatin $(0,2,4,8,16,32$ or $64 \mu \mathrm{mol} / \mathrm{l})$ for $48 \mathrm{~h}$. (B) MTT cell viability assays in the COL11 A1-silenced H520 cells and COL11 A1-overexpressing H23 cells treated with cisplatin ( $8 \mu \mathrm{mol} / \mathrm{l})$ at different time-points $(0,12,24,36,48,60$ and $72 \mathrm{~h}) .{ }^{*} \mathrm{P}<0.05$ compared with the control cells.

A

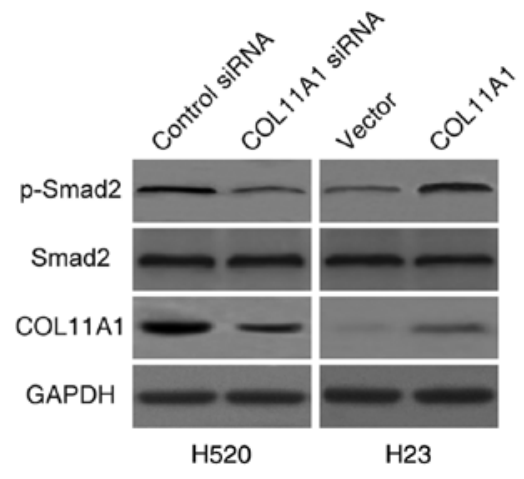

D

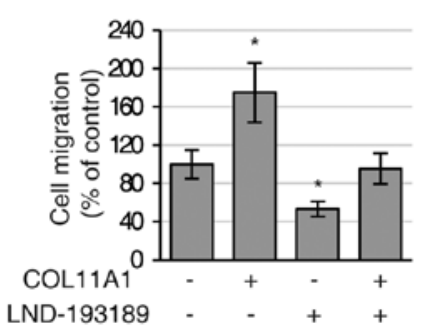

B

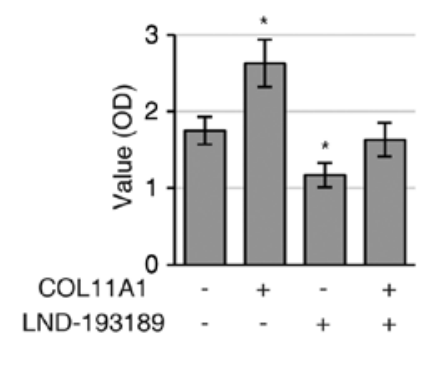

E

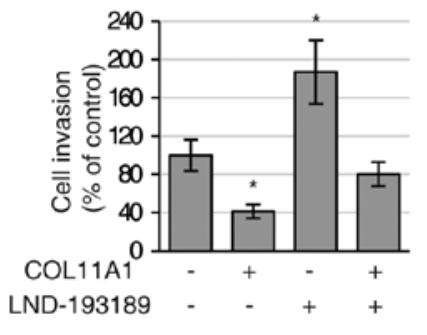

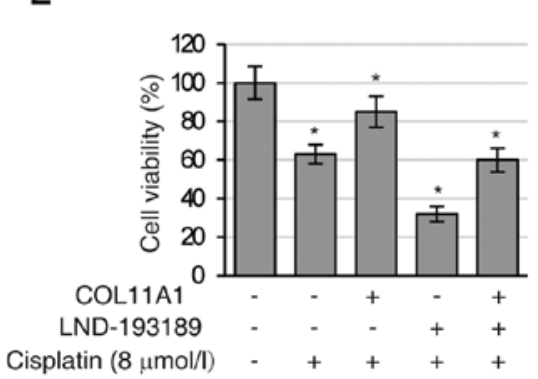

Figure 6. Regulation of NSCLC cells by COL11A1 through the Smad signaling pathway. (A) Smad,p-Smad2 and COL11A1 expression in the COL11A1-silenced H520 cells and COL11A1-overexpressing H23 cells. GAPDH was used as a loading control. MTT (B), wound-healing (C) and Transwell (D) assays in ithe ndicated $\mathrm{H} 23$ cells. (E) Cell viability assays in the indicated $\mathrm{H} 23$ cells incubated with cisplatin ( $8 \mu \mathrm{mol} / \mathrm{l})$ or in combination with COL11A1 and or LND-193189 for $48 \mathrm{~h}$. "P<0.05 compared with the control cells. 
adenocarcinoma and squamous cell carcinoma (28). A clear understanding of the correlation between COL11A1 overexpression and the subtypes of NSCLC may be required for the clinical application of COL11A1 as a biomarker for the diagnosis and prediction of relapse in patients with NSCLC.

COL11A1 has been indicated as a potential metastasis-associated gene in cancers, such as lung cancer and breast cancer $(29,30)$. In the present study, we further found that COL11A1 enhanced cell proliferation, migration and invasion in NSCLC cells. After screening the endogenous expression levels of COL11A1, COL11A1 was found to be overexpressed in the $\mathrm{H} 23$ cells. Ectopic overexpression of COL11A1 significantly enhanced cell proliferation, migration and invasive capacity in vitro. Conversely, siRNA-mediated depletion of COL11A1 reduced cell proliferation, migration and invasive capacity in H520 cells. The role of Smad signaling has been extensively studied in human cancers, particularly in tumor progression and metastasis $(31,32)$. Moreover, Smad signaling was found to directly promote tumor growth in NSCLC (33). In the present study, Smad signaling was activated by overexpression of COL11A1, and inhibition of Smad signaling abolished the promotive effect of COL11A1 overexpression on cell proliferation and migration. Integrins have been reported to activate Smad phosphorylation in many cell types $(34,35)$. We hypothesized that integrins are the main cell surface receptors of COL11A1, and COL11A1 regulates Smad phosphorylation via binding to integrins.

We further found that COL11 A1 is associated with chemoresistance in NSCLC cells. Cisplatin, a platinum-based drug, has been used for the treatment of a wide array of different human solid tumors (36). However, the development of resistance to cisplatin is one of the most important obstacles to effective treatment (37). Our results showed that COL11A1 was induced by cisplatin treatment in a dose-dependent manner, and overexpression of COL11A1 resulted in chemoresistance. We also elucidated that COL11A1 confers chemoresistance via activation of Smad signaling in NSCLC cells. In addition, the best known function of cisplatin for cancer treatment is induction of target cell apoptosis by generation of DNA lesions (38). Several molecular mechanisms are involved in cisplatin resistance, and investigation of the mechanisms whereby COL11A1 is incorporated into signaling transduction in chemoresistance is warranted.

In summary, we revealed that COL11A1 is overexpressed in both metastatic NSCLC and recurrent NSCLC tissues. COL11A1 enhanced cell proliferation, migration and invasive capacity in NSCLC cell lines, and conferred the development of resistance to cisplatin via activation of Smad signaling. COL11 A1 is a potential molecular marker with which to identify and predict the outcome of patients with NSCLC. Moreover, our results highlight the importance of COL11A1 in NSCLC tumor progression and chemoresistance, indicating potential therapies that target COL11A1 or the Smad signaling pathway.

\section{References}

1. Peters S, Adjei AA, Gridelli C, Reck M, Kerr K and Felip E ESMO Guidelines Working Group: Metastatic non-small-cell lung cancer (NSCLC): ESMO Clinical Practice Guidelines for diagnosis, treatment and follow-up. Ann Oncol 23 (Suppl 7): vii56-vii64, 2012.
2. The Surveillance, Epidemiology, and End Results (SEER) Program of the National Cancer Institute: SEER Cancer Statistics Review, 1975-2011. National Cancer Institute, Bethesda, MD, 2011.

3. Molina JR, Yang P, Cassivi SD, Schild SE and Adjei AA: Non-small cell lung cancer: Epidemiology, risk factors, treatment, and survivorship. Mayo Clin Proc 83: 584-594, 2008.

4. Beckles MA, Spiro SG, Colice GL and Rudd RM: Initial evaluation of the patient with lung cancer: Symptoms, signs, laboratory tests, and paraneoplastic syndromes. Chest 123 (Suppl 1): 97S-104S, 2003.

5. Reck M,Heigener DF,Mok T, Soria JC and Rabe KF: Management of non-small-cell lung cancer: Recent developments. Lancet 382: 709-719, 2013.

6. Van Schil PE, Balduyck B, De Waele M, Hendriks JM, Hertoghs M and Lauwers P: Surgical treatment of early-stage non-small-cell lung cancer. EJC Suppl 11: 110-122, 2013.

7. Heide J, Hinkelbein W, Schmittel A and Kaiser D (eds): Controversies in the Treatment of Lung Cancer. Karger Medical and Scientific Publishers, Basel, 2010.

8. Martini N, Bains MS, Burt ME, Zakowski MF, McCormack P, Rusch VW and Ginsberg RJ: Incidence of local recurrence and second primary tumors in resected stage I lung cancer. J Thorac Cardiovasc Surg 109: 120-129, 1995.

9. Mountain CF: Revisions in the international system for staging lung cancer. Chest 111: 1710-1717, 1997.

10. Brock MV, Hooker CM, Ota-Machida E, Han Y, Guo M, Ames S, Glöckner S, Piantadosi S, Gabrielson E, Pridham G, et al: DNA methylation markers and early recurrence in stage I lung cancer. N Engl J Med 358: 1118-1128, 2008.

11. Kinch MS, Moore MB and Harpole DH Jr: Predictive value of the EphA2 receptor tyrosine kinase in lung cancer recurrence and survival. Clin Cancer Res 9: 613-618, 2003.

12. McFarlane C, McFarlane S, Paul I, Arthur K, Scheaff M, Kerr K, Stevenson M, Fennell DA and Johnston JA: The deubiquitinating enzyme USP17 is associated with non-small cell lung cancer (NSCLC) recurrence and metastasis. Oncotarget 4: 1836-1843, 2013.

13. Mio F, Chiba K, Hirose Y, Kawaguchi Y, Mikami Y, Oya T, Mori M, Kamata M, Matsumoto M, Ozaki K, et al: A functional polymorphism in COL11A1, which encodes the alpha 1 chain of type XI collagen, is associated with susceptibility to lumbar disc herniation. Am J Hum Genet 81: 1271-1277, 2007.

14. Prockop DJ, Kivirikko KI, Tuderman L and Guzman NA: The biosynthesis of collagen and its disorders (first of two parts). N Engl J Med 301: 13-23, 1979.

15. Nimni M and Harkness R: Molecular structures and functions of collagen. Collagen 1: 1-77, 1988.

16. Li Y, Lacerda DA, Warman ML, Beier DR, Yoshioka H, Ninomiya Y, Oxford JT, Morris NP, Andrikopoulos K, Ramirez F, et al: A fibrillar collagen gene, Col11a1, is essential for skeletal morphogenesis. Cell 80: 423-430, 1995.

17. Donoso LA, Edwards AO, Frost AT, Ritter R III, Ahmad N, Vrabec T, Rogers J, Meyer D and Parma S: Clinical variability of Stickler syndrome: Role of exon 2 of the collagen COL2A1 gene. Surv Ophthalmol 48: 191-203, 2003.

18. Annunen S, Körkkö J, Czarny M, Warman ML, Brunner HG, Kääriäinen H, Mulliken JB, Tranebjaerg L, Brooks DG, Cox GF, et al: Splicing mutations of 54-bp exons in the COL11A1 gene cause Marshall syndrome, but other mutations cause overlapping Marshall/Stickler phenotypes. Am J Hum Genet 65: 974-983, 1999.

19. Wu YH, Chang TH, Huang YF, Huang HD and Chou CY: COL11A1 promotes tumor progression and predicts poor clinical outcome in ovarian cancer. Oncogene 33: 3432-3440, 2014.

20. Sok JC, Lee JA, Dasari S, Joyce S, Contrucci SC, Egloff AM, Trevelline BK, Joshi R, Kumari N, Grandis JR, et al: Collagen type XI $\alpha 1$ facilitates head and neck squamous cell cancer growth and invasion. Br J Cancer 109: 3049-3056, 2013.

21. Wu YH, Chang TH, Huang YF, Chen CC and Chou CY: COL11A1 confers chemoresistance on ovarian cancer cells through the activation of Akt/c/EBP $\beta$ pathway and PDK1 stabilization. Oncotarget 6: 23748-23763, 2015.

22. Chong IW, Chang MY, Chang HC, Yu YP, Sheu CC, Tsai JR, Hung JY, Chou SH, Tsai MS, Hwang JJ, et al: Great potential of a panel of multiple hMTH1, SPD, ITGA11 and COL11A1 markers for diagnosis of patients with non-small cell lung cancer. Oncol Rep 16: 981-988, 2006. 
23. Fischer H, Stenling R, Rubio C and Lindblom A: Colorectal carcinogenesis is associated with stromal expression of COL11A1 and COL5A2. Carcinogenesis 22: 875-878, 2001.

24. Tanoue LT: Staging of non-small cell lung cancer. Semin Respir Crit Care Med 29: 248-260, 2008.

25. D'Amico TA, Aloia TA, Moore MB, Conlon DH, Herndon JE II, Kinch MS and Harpole DH Jr: Predicting the sites of metastases from lung cancer using molecular biologic markers. Ann Thorac Surg 72: 1144-1148, 2001.

26. Mountain CF: The international system for staging lung cancer. Semin Surg Oncol 18: 106-115, 2000.

27. Taylor MD, Nagji AS, Bhamidipati CM, Theodosakis N, Kozower BD, Lau CL and Jones DR: Tumor recurrence after complete resection for non-small cell lung cancer. Ann Thorac Surg 93: 1813-1821, 2012.

28. Wang KK, Liu N, Radulovich N, Wigle DA, Johnston MR, Shepherd FA, Minden MD and Tsao MS: Novel candidate tumor marker genes for lung adenocarcinoma. Oncogene 21: 7598-7604, 2002.

29. Bignotti E, Tassi RA, Calza S, Ravaggi A, Bandiera E, Rossi E, Donzelli C, Pasinetti B, Pecorelli S and Santin AD: Gene expression profile of ovarian serous papillary carcinomas: Identification of metastasis-associated genes. Am J Obstet Gynecol 196: 245.e1-e11, 2007.

30. Ellsworth RE, Seebach J, Field LA, Heckman C, Kane J, Hooke JA, Love B and Shriver CD: A gene expression signature that defines breast cancer metastases. Clin Exp Metastasis 26 205-213, 2009
31. Miyazono K, Suzuki H and Imamura T: Regulation of TGF- $\beta$ signaling and its roles in progression of tumors. Cancer Sci 94: 230-234, 2003

32. Akhurst RJ and Derynck R: TGF- $\beta$ signaling in cancer - a double-edged sword. Trends Cell Biol 11: S44-S51, 2001.

33. Jeon HS and Jen J: TGF-beta signaling and the role of inhibitory Smads in non-small cell lung cancer. J Thorac Oncol 5: 417-419, 2010.

34. Li W, Liu Z, Zhao C and Zhai L: Binding of MMP-9-degraded fibronectin to $\beta 6$ integrin promotes invasion via the FAK-Src-related Erk1/2 and PI3K/Akt/Smad-1/5/8 pathways in breast cancer. Oncol Rep 34: 1345-1352, 2015.

35. Chen X, Wang H, Liao HJ, Hu W, Gewin L, Mernaugh G, Zhang S, Zhang ZY, Vega-Montoto L, Vanacore RM, et al: Integrin-mediated type II TGF- $\beta$ receptor tyrosine dephosphorylation controls SMAD-dependent profibrotic signaling. J Clin Invest 124: 3295-3310, 2014.

36. Kelland L: The resurgence of platinum-based cancer chemotherapy. Nat Rev Cancer 7: 573-584, 2007.

37. Chang A: Chemotherapy, chemoresistance and the changing treatment landscape for NSCLC. Lung Cancer 71: 3-10, 2011.

38. Galluzzi L, Senovilla L, Vitale I, Michels J, Martins I, Kepp O, Castedo M and Kroemer G: Molecular mechanisms of cisplatin resistance. Oncogene 31: 1869-1883, 2012. 